\title{
Electrical Properties of Graphene / Natural Rubber Nanocomposites Coated Nylon 6.6 Fabric under Cyclic Loading
}

\author{
Hasan Kasım¹, Murat Yazıcı ${ }^{1 *}$ \\ ${ }^{1}$ Department of Automotive Engineering, Faculty of Engineering, Uludag University, TR16059 Nilufer/ Bursa, Turkey \\ *Corresponding author, email: myazici@uludag.edu.tr
}

Received: 20 February 2018, Accepted: 23 May 2018, Published online: 18 June 2018

\begin{abstract}
In the present study, an elastomeric nanocomposite was prepared by two roller mixing mill with the Natural Rubber (NR) and Nano Graphene Platelets (NGP). The Nylon 6.6 cord fabrics were laminated with the prepared NR/NGP nanocomposite layers. The NR/NGP composites and Nylon 6.6 cord fabric laminated nanocomposite plates were cured at $165^{\circ} \mathrm{C}$ for 10 min under pressure. Nylon 6.6 fabric reinforced NR/NGP nanocomposites were electrically characterized under free and cyclic loading conditions. NGP addition to NR improved the electrical conductivity. Under cyclic loading produced nanocomposite and cord fabric layered plates showed periodical sensing behavior with same amplitude in each period.
\end{abstract}

Keywords

nanocomposite, Graphene, Natural Rubber, cyclic loading

\section{Introduction}

Nanostructured materials gained great importance in the past decade on account of their wide range of potential applications in many areas. These materials are used for the development of a new generation of composite materials [1-6]. NGPs are one of the gorgeous reinforcing material for new generation multifunctional composite materials. It is the first two-dimensional (2D) atomic crystal available to us. It has attracted considerable attention in recent years because of its high Young's modulus, fracture toughness, very high electrical and thermal conductivity, large specific surface area, excellent barrier properties, and the quantum Hall effect even at room temperature. These excellent properties present a growing number of advanced technological applications such as solar cells, field effect devices, a wide range of practical chemical and strain sensors, highly flexible transparent electrodes by a variety of nanocomposites [7, 8]. NR, a crucial elastomer material, has been widely used in various industries due to its distinguished comprehensive performance, such as unique processability, high strength, endurance life and resilience, excellent tear resistance, superior building tackiness, etc. [9]. Polymer cord fabrics are widely used for reinforcing the rubber matrix materials to obtain composite materials to produce various industrial rubber products etc. tires, air spring, and belting. Polymer cord fabric, as a reinforcing material in a rubber matrix, plays a vital role in endowing rubber with sufficient modulus to resist high strain without permanent deformation and damages [10]. In this study, excellent properties and conformity of the NR/NGP/cord fabric combined as a layered composite structure to obtain electrical conductive, high fatigue and static tensile-compression strength, and flexible material for low to high strain sensing under static and cyclic loads.

\section{Materials and Methods}

\subsection{Materials}

NGPs were received from Nanographi Co. / Turkey. They have $99.5 \%$ purity, averagely $6 \mathrm{~nm}$ thickness and $16 \mu \mathrm{m}$ diameter, $150 \mathrm{~m}^{2} / \mathrm{g}$ specific surface area, and 1100-1600 s/m electrical conductivity and grey color. In Fig. 1 SEM photo of the used NGP was presented.

In this study, used NR matrix material was a kind of the Natural Rubber-based composite. It was obtained by mixing of the Standart Vietnam Rubber (Vietnam SVR 10) [11], Cis Polybutadiene Rubber (CBR 1203) [12], Styrene Butadiene Rubber (SBR 1502) [13], Carbon Black, other filler materials, and chemicals. The matrix material receipt is given 


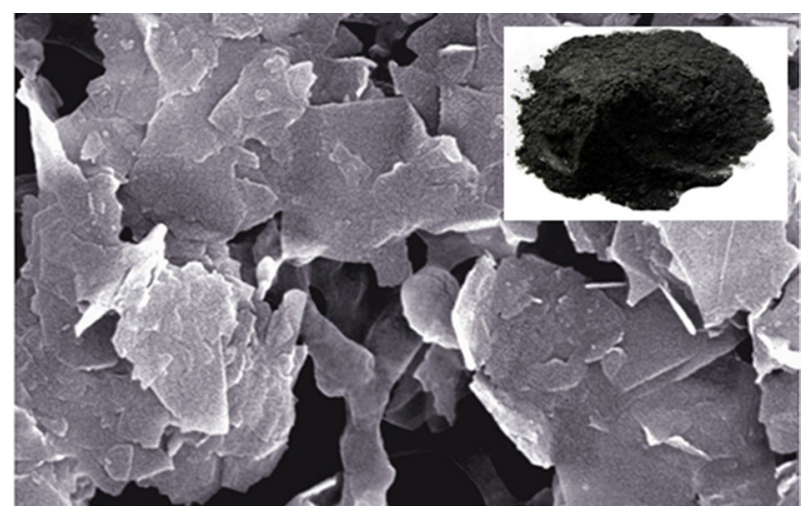

Fig. 1 SEM picture of the used Graphene materials [14].

in Table 1 as coded BR00 compound. Billas Co. / Turkey supplied all rubber materials and filler chemicals used in the Natural Rubber matrix. Cord fabric was 1400x2-120 dtx (PA 6.6 yarns) and received from KordSA Co. / Turkey.

\subsection{Production Technique}

NR, base Carbon Black filler and other chemicals (accelerators, plasticizers, aromatic oil and wax, etc.) concentrations (as phr) of master stage mixture were incorporated into the rubber matrix using internal dispersion mixer at $110^{\circ} \mathrm{C}$ for thirty minutes. Then the post-mixing of NGP fillers in different phr's with the addition of crosslinker

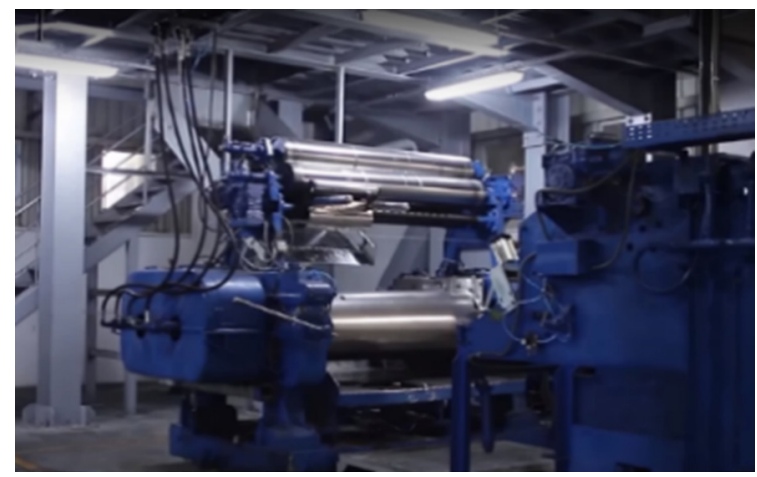

(a)

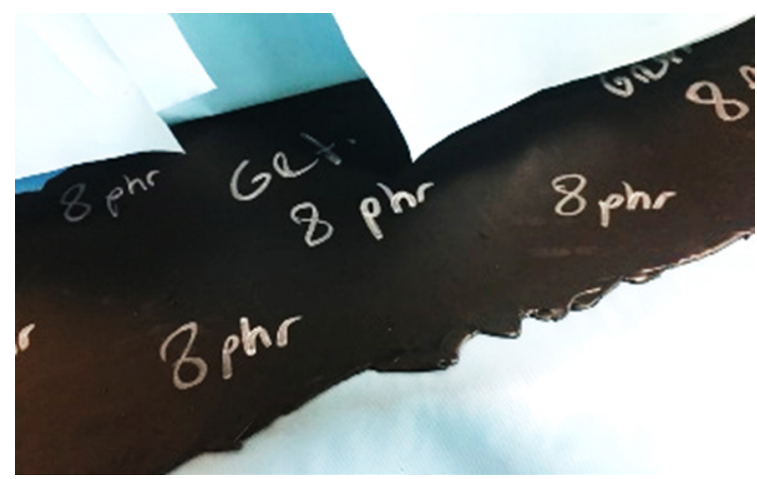

(c) (sulfur), accelerators and activators in the master stage mixture NR matrix was carried out using two rollers mixing mill at temperature $70{ }^{\circ} \mathrm{C}$ and $40 \mathrm{rpm}$ roller's speed for 25 minutes. Four different recipes were prepared by using Billas Co.'s production equipment (Fig. 2a). Obtained nanocomposites were stacked using PE sheet separators (Fig. 2b). All incorporated materials such as the rubbers, fillers and the vulcanizing additives (chemicals, oils, etc.). are given in Table 1, expressed as parts per hundred parts of rubber (phr). The produced NR/NGP composites labeled according to NGP phr's (Fig. 2c).

After the mixing process, the mixture was kept in a climatic room at a $21{ }^{\circ} \mathrm{C}$ temperature along 24 hours with the purpose of rest of the materials (Fig. 2d). Each rubber mixture was weighed on a precision scale with $5 \%$, five pieces of rubber plates of each recipe were vulcanized. The vulcanization process was carried out successively while keeping all the conditions the same.

The NR/NGP nanocomposites were vulcanized under the hot stamping at $165{ }^{\circ} \mathrm{C}$ along 8 minutes. After the vulcanization process, NR plates were removed from the mold. Cord fabric reinforced NR/NGP layered composites were produced in two-steps. Initially, non-vulcanized NR/NGP plies at $0.8 \mathrm{~mm}$ thickness were obtained from the rubber blend subjecting only pressure without any temperature

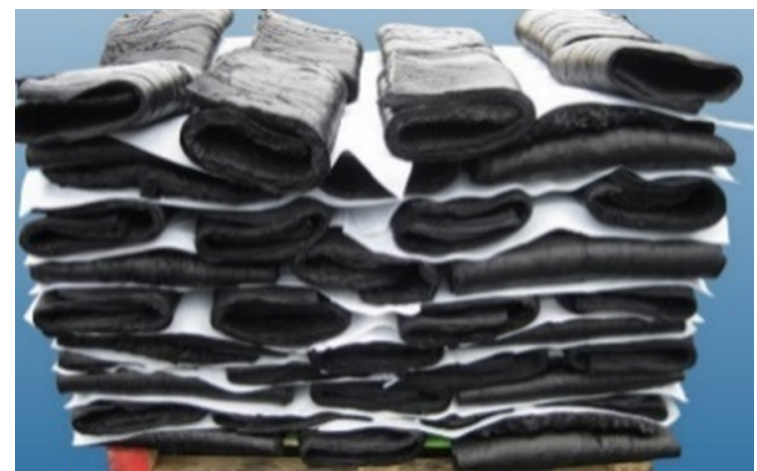

(b)

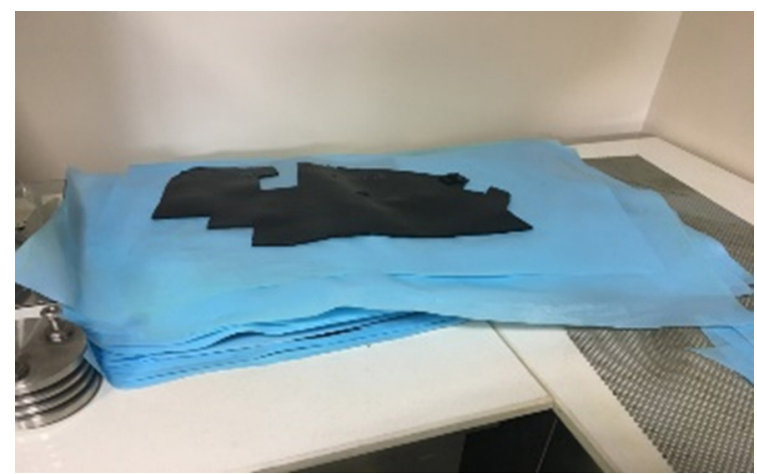

(d)

Fig. 2 a) NR/NGP composite mixing mill b) Stacking mixed different type of nanocomposites c) Coded GF/NR nanocomposite matrix before curing and cord fabric coating d) Resting nanocomposite materials in the laboratory conditions. 
Table 1 Formulation and additives used in the preparation of NR nanocomposites.

\begin{tabular}{|c|c|c|c|c|c|c|c|c|c|c|c|c|c|c|}
\hline \multirow[b]{2}{*}{ Compounds } & \multicolumn{3}{|c|}{ Rubber Groups } & \multicolumn{3}{|c|}{ Filler Groups } & \multicolumn{5}{|c|}{ Chemicals } & \multirow{2}{*}{$\begin{array}{c}\text { Oils } \\
\text { Paraffinic } \\
\text { Oil }\end{array}$} & \multicolumn{2}{|c|}{ Vulcanizers } \\
\hline & $\begin{array}{c}\text { SVR } \\
10\end{array}$ & $\begin{array}{l}\text { SBR } \\
1502\end{array}$ & $\begin{array}{l}\text { CBR } \\
1203\end{array}$ & $\begin{array}{c}\text { FEF } \\
\text { N.550 }\end{array}$ & $\begin{array}{l}\text { 2.FEF } \\
\text { N.550 }\end{array}$ & Graphene & $\mathrm{ZNO}$ & $\begin{array}{c}\text { Stearic } \\
\text { Acid }\end{array}$ & IPPD & $\begin{array}{c}\text { Ozone } \\
\text { Wax }\end{array}$ & TMQ & & $\mathrm{S} 80$ & CBS \\
\hline BR00 & 37.3 & 28.8 & 33.9 & 59.8 & 8 & 0 & 2.2 & 2 & 1 & 1 & 1 & 20.34 & 2.03 & 1.19 \\
\hline GRF01 & 37.3 & 28.8 & 33.9 & 59.8 & 0 & 1 & 2.2 & 2 & 1 & 1 & 1 & 20.34 & 2.03 & 1.19 \\
\hline GRF04 & 37.3 & 28.8 & 33.9 & 59.8 & 0 & 4 & 2.2 & 2 & 1 & 1 & 1 & 20.34 & 2.03 & 1.19 \\
\hline GRF08 & 37.3 & 28.8 & 33.9 & 59.8 & 0 & 8 & 2.2 & 2 & 1 & 1 & 1 & 20.34 & 2.03 & 1.19 \\
\hline
\end{tabular}

(Fig. 3a). Secondly, unidirectional cord fabrics were placed between two NR/NGP non-vulcanized composite plies and then vulcanized at $165^{\circ} \mathrm{C}$ along 8 minutes (Fig. 3b) under pressure. After the vulcanization process, compression molded cord fabric reinforced NR/NGP nanocomposite laminate were removed from the mold (Fig. 3c). Moreover, the specimens for tensile and compression tests were produced in the molds. After the vulcanization, all specimens were kept minimum 16 hours at room temperature.

\subsection{Experimental Set-up}

In the developed NR/NGP composites were produced 4 different types. NR matrix is a combination of Natural Rubber latex and various particulate fillers. Filler content was kept at 70 phr. NGP fillers in the NR/NGP nanocomposites were selected as $0,1,4$, and 8 phr's.

Fig. 4 shows NGP/NR nanocomposites specimen configurations for all test types. Compression specimens have 29 $\mathrm{mm}$ diameter and $12.7 \mathrm{~mm}$ height (ASTM D 395). Tensile specimens are shaped like a dumb-bell (see Fig. 5a). The dimensions selected by following the ASTM D 412 standard and produced by using a cutting die. The cutting die's technical drawing is demonstrated in Fig. 5b.

A constant current source (Keithley Instruments Model 6221) was used to generate regular Direct Current (DC) flow for electrical characterization of the developed materials. Four probe technique was applied to measure electrical resistance drop between two probes using a digital multimeter (Keithley Instruments Model 2000 DMM) with two Keithley 6814 Electrometers and recorded using a LabView system. The electrical characterization experimental setup is presented in Fig. 6 .

\section{Results and discussion}

\subsection{Density Measurement}

At least three different measurements were made for each composite, and their average values were calculated (ASTM D 297). Density values were measured very close to each other as NR(BR00) $1.1133 \mathrm{~g} / \mathrm{cm}^{3}, 1 \mathrm{phr}$ NGP/NR (GRF01) $1.1043 \mathrm{~g} / \mathrm{cm}^{3}, 4$ phr NGP/NR (GRF04) $1.1051 \mathrm{~g} / \mathrm{cm}^{3}$ and $8 \mathrm{phr}$ NGP/NR (GRF08) $1.1108 \mathrm{~g} / \mathrm{cm}^{3}$. The densities of the produced nanocomposite materials are close to each other due to only changing NGP amount in the content. Furthermore, NGP has a very low density, and NGP percentage in the all studied NGP/NR composites are relatively small comparing to NR rubber amount.

\subsection{Hardness Experiments (Shore A)}

The hardness of the developed materials using tensile and compression specimens was measured using at least 5 different measurements. The measurement were performed on each mixture's tensile and compression specimens, and
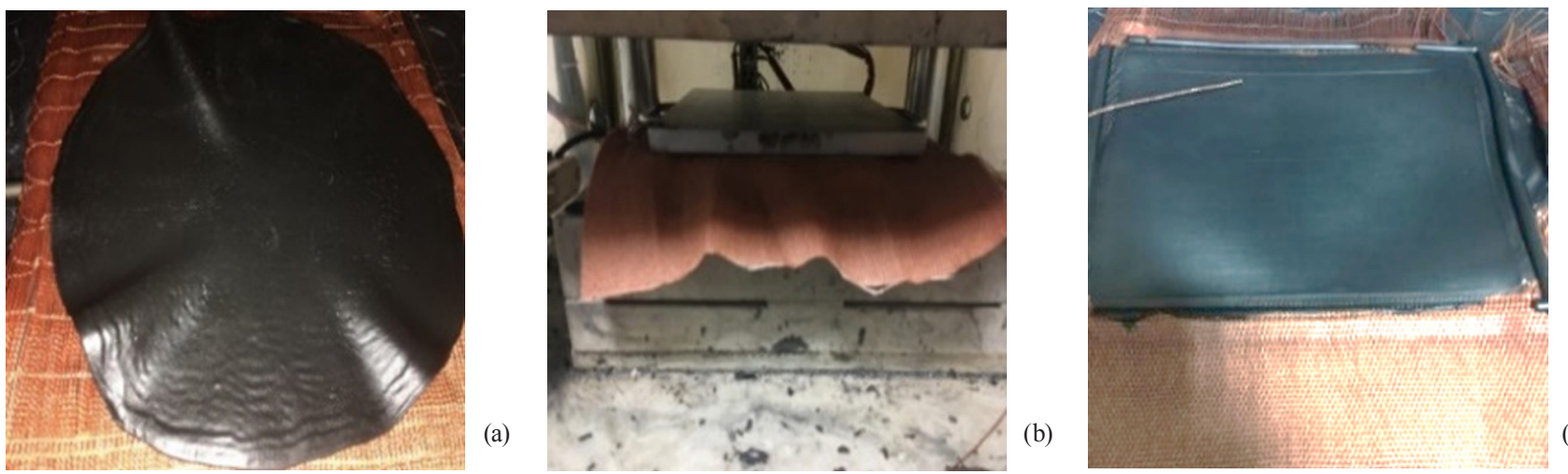

Fig. 3 Production of Cord Fabric/ NR-NGP composite materials: a) Preformed thin NR/NGP sheet before curing b) Cord fabric coating process under hot pressing in a mold c) Vulcanized Cord Fabric/NR-NGP composite plate. 


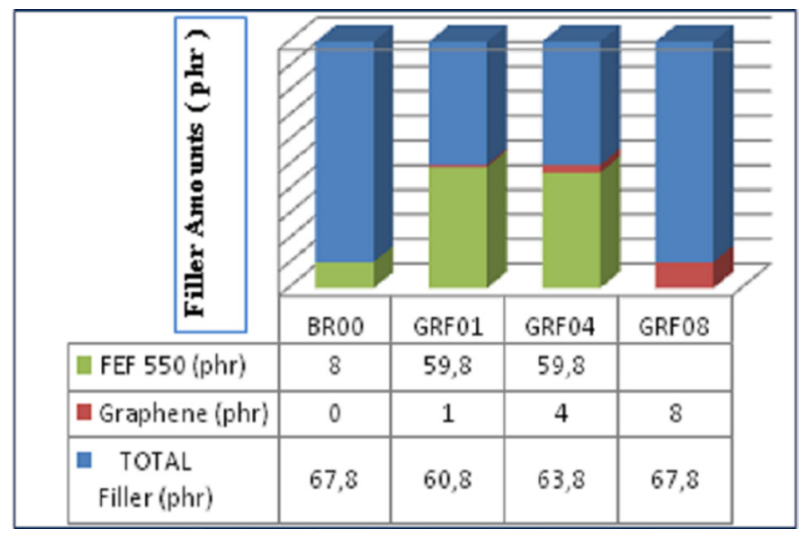

Fig. 4 Studied NR/NGP composites for four different content.
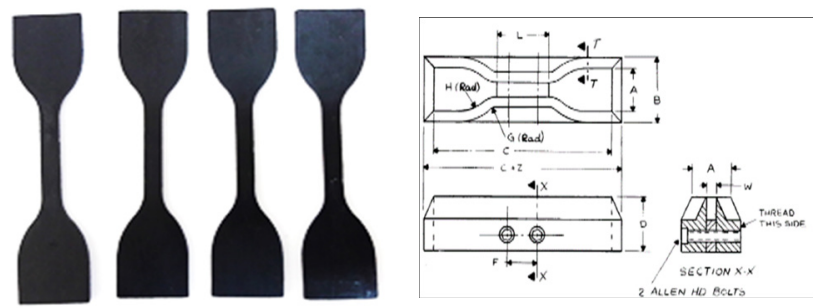

(a)

(b)

Fig. 5 a) Produced tensile specimen examples b) Tensile specimen cutting die

their average values were calculated. The measurement results are given in Fig. 7.

\subsection{Compression Experiments}

Compression tests of nanocomposites were conducted at Zwick Proline Z010 TH Universal Tensile-Compression test machine. Experiments were realized at $15 \mathrm{~mm} / \mathrm{min}$ constant crosshead speed and $5 \mathrm{~N}$ preload. Fig. 8 shows the obtained compression test results of the produced materials.
In Fig. 8 Compression load and displacement test results were presented depend on NGP amount. The NGP incorporation into the base rubber reduced the load carrying capacity of the NR in a small amount. However, the behavior of the NR/NGP nanocomposite load-displacement curves shown almost same behavior according to NGP filler amount. In the compression tests, it is observed that beyond $70 \%$ displacement, the specimens were damaged.

Hysteresis experiments were obtained as compression and relaxation load-displacement measurements. The area between loading and unloading curves shows absorbed energy. This energy dissipates by internal friction of the molecular rubber chains. In Fig. 9, curves show variations with each other even low NGP filling percentages.

In Table $2, \mathrm{~h}_{0}$ initial height of the specimen, $\mathrm{W}_{\text {Fapply }}$ applied energy (area under the first curve, which is obtained by loading case), $\mathrm{W}_{\text {Frem }}$ relaxed energy (area under the second curve which is received by unloading case), and $\Delta \mathrm{W}$ is absorbed energy. Amount of the absorbed energies were affected by the addition of the NGP in different characters. By 1 phr NGP addition, the absorbed energy was reduced concerning the base rubber (BR00). However, 4 and 8 phr NGP addition improved the energy absorption properties of the base rubber.

\subsection{Tensile Experiments}

Tensile tests were realized in Zwick tensile testing machine at $200 \mathrm{~mm} / \mathrm{min}$ constant speed and $5 \mathrm{~N}$ preload according to ASTM D 412 Standard. At least 5 different measurements were carried out from each mixture, and their average values were calculated. Results are given in Fig. 10. The results show that NGP addition to

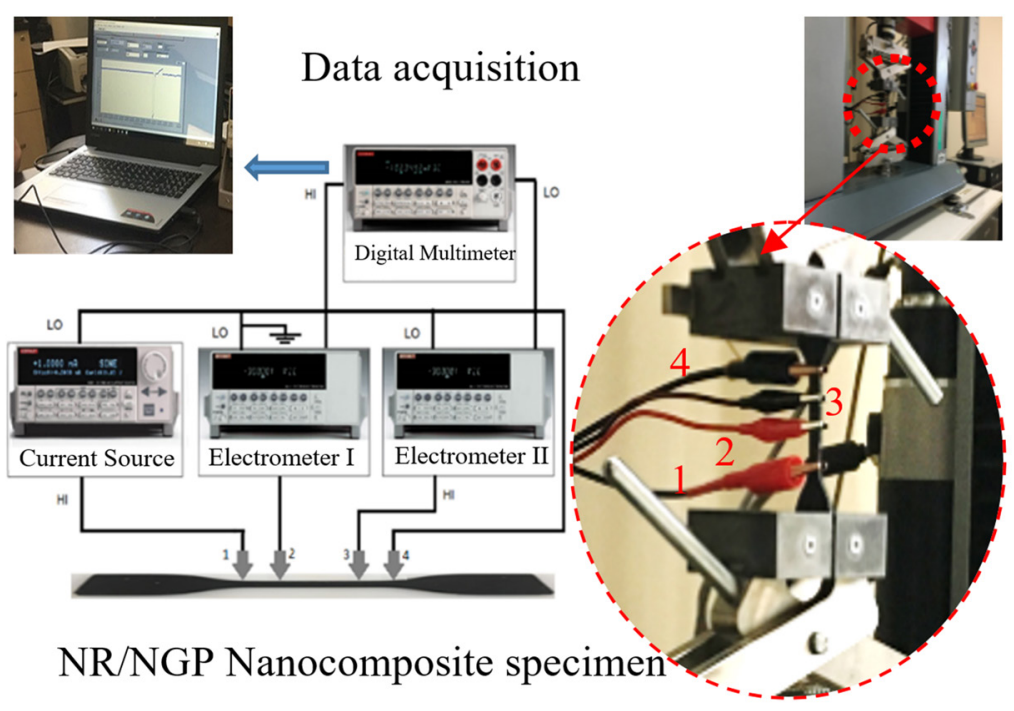

Fig. 6 The electrical characterization experimental setup. 

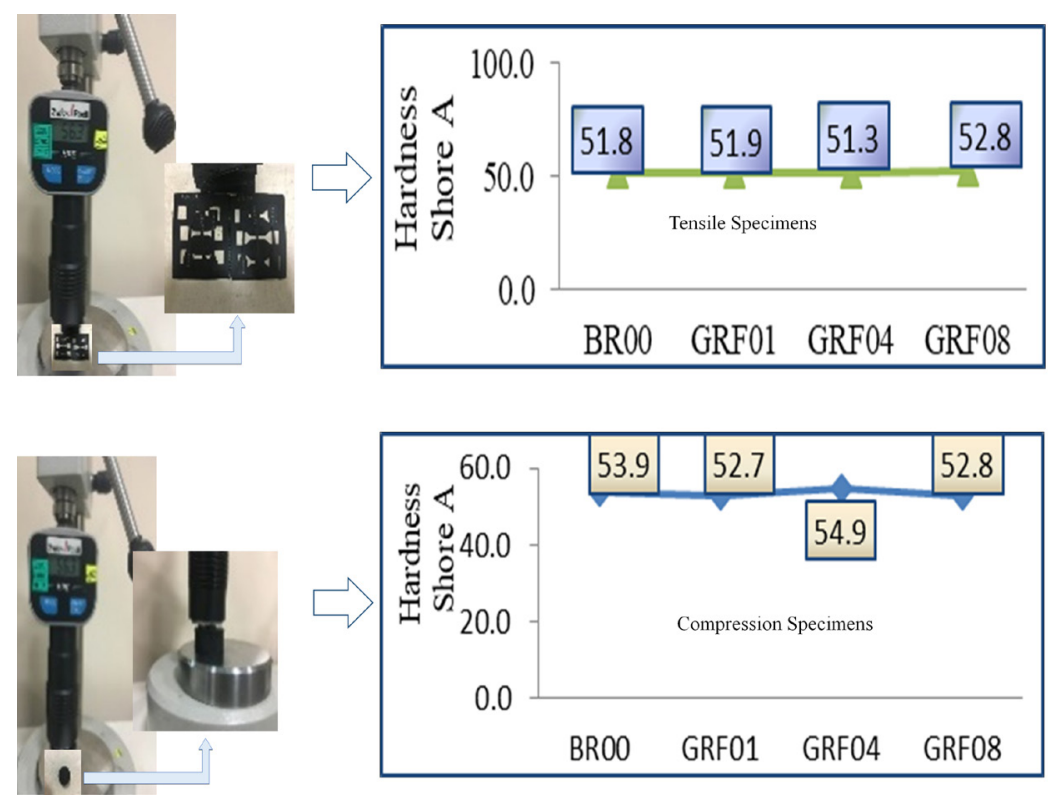

Fig. 7 Hardness measurements equipment and variation of the hardness in the produced tensile and compression specimens.

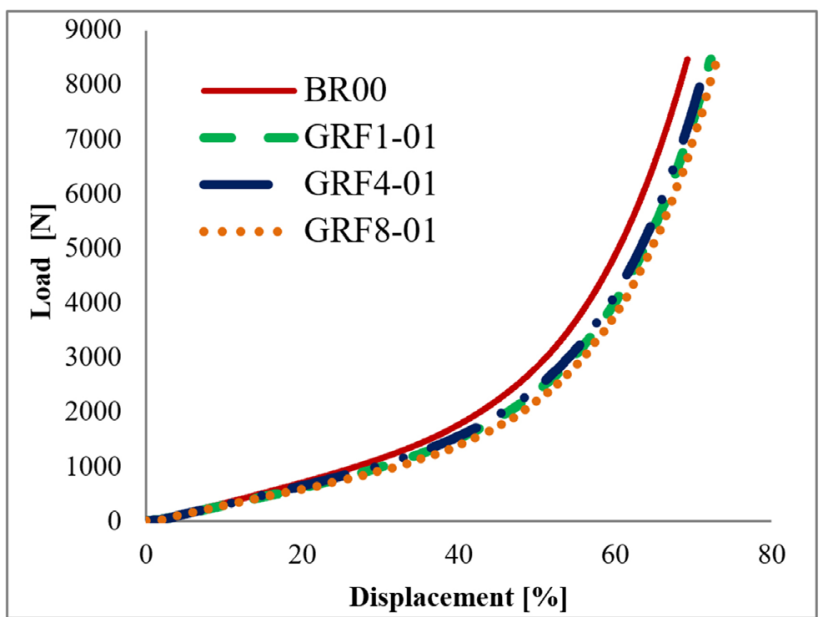

Fig. 8 Compression test results.

Table 2 Absorbed energy during compression-relaxation loading.

\begin{tabular}{lcccc}
\hline & $\mathrm{h}_{0}$ & $\mathrm{~W}_{\text {Fapply }}$ & $\mathrm{W}_{\text {Frem }}$ & $\Delta \mathrm{W}$ \\
& $\mathrm{mm}$ & $\mathrm{N} . \mathrm{mm}$ & $\mathrm{N} . \mathrm{mm}$ & N.mm \\
\hline BR00 & 14.65 & 19891.90 & 8267.02 & 11624.88 \\
GRF01 & 14.74 & 19758.99 & 10031.11 & 9727.88 \\
GRF04 & 14.86 & 20035.37 & 8235.82 & 11799.55 \\
GRF08 & 14.76 & 19164.24 & 6911.41 & 12252.83 \\
\hline
\end{tabular}

base rubber is affecting the tensile behavior. Such that, 1 phr NGP filled specimens demonstrate precisely same behavior as base rubber compound. When rising NGP amount to 4 phr, the strength show $11.5 \%$ increase in 490 $\%$ strain. However, stepping up to $8 \mathrm{phr}$ NGP filling, the strength reduced as $20.37 \%$ at $590 \%$ strain. All materials show nonlinear behavior up to $200 \%$ strain level, after

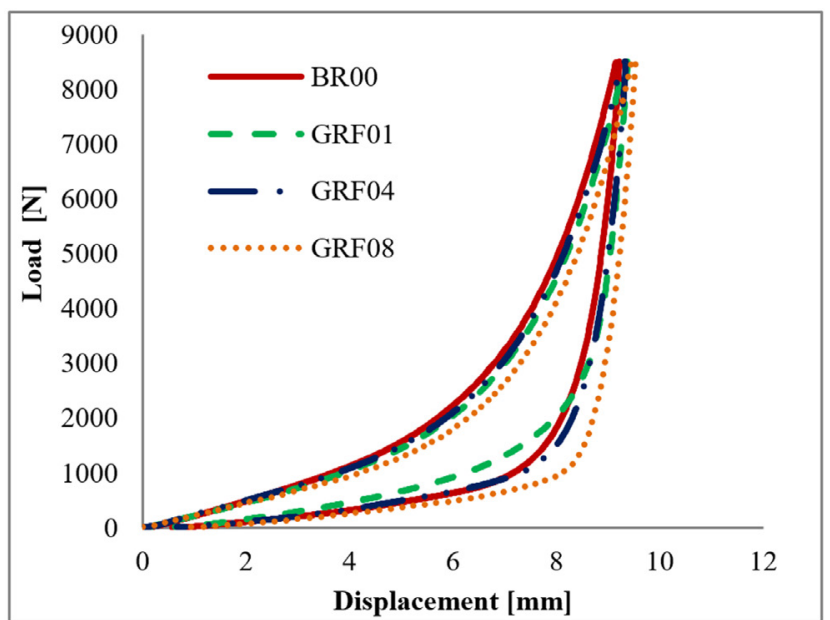

Fig. 9 Loading and unloading experimental results.

that, they behave as perfect linear. These experiments also show that the failure strain reduces by comparing to base rubber with adding NGP. The rigidity of the base rubber changed with higher than 1 phr NGP content. In 4 phr NGP addition rised the rigidity and 8 phr addition reduced as same as strength behavior. That means, the NGP content beyond a certain amount does not improve the tensile behavior.

\subsection{Tearing Experiments}

Tearing tests of the produced NR/NGP composites were conducted using ASTM D624 test standard. The LoadDisplacement curves were given in Fig. 11. These figures show that the NGP content did not change the total resistivity of the crack propagation in the base rubber. The 


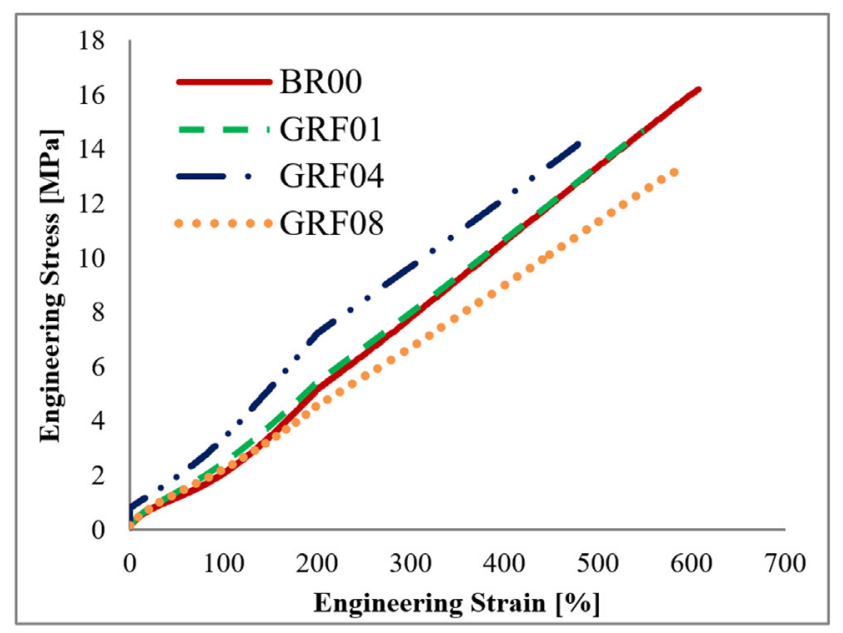

Fig. 10 Quasi-static tensile test results.

post-mortem pictures are given in Fig. 12; these images show that all types of the tear strength specimens have same crack initiation and propagation behavior. Moreover, failure sections, paths, and shapes almost identical in all type of the specimens. The CB and NGP rigid nano particulates were caused the secondary crack initiation and the crack bridging. The crack path directional variations near the notch tip can be seen in Fig. 12d.

\subsection{Curing Characteristics}

Curing characterization study of the nanocomposites was carried out in the Montech Rheometer (MDR 3000) testing instrument at $165^{\circ} \mathrm{C}$ along 8 minutes. Table 3 shows the curing features of the NGP filled NR based nanocomposites in the presence of CB. The scorch time $\left(t_{\mathrm{s} 2}\right)$ and cure time $\left(t_{90}\right)$ of the NGP filled rubber nanocomposites are the same as NR without NGP filler. However, as the amount of NGP filler was increased, the curing time also decreased a little. The reason for the shorter cure time of the NR/NGP nanocomposites is the increased thermal transition of NR in the presence of NGP.

Torque values which indicate the improved interaction behavior and good interfacial adhesion between cord fiber and the fillers as well as with the NR matrix. In this study, the maximum torque $\left(\mathrm{M}_{\mathrm{H}}\right)$ value was decreased by the NGP filling for their respective control. Raising up NGP percentage in the NGP/NR nanocomposites, caused to the reduction of the $M_{H}$ value due to slipping Nano Graphene Platelets on each other. In the minimum torque $\left(\mathrm{M}_{\mathrm{L}}\right)$ value increased for the NGP loaded nanocomposites. However, the $M_{L}$ reduced by increasing the NGP mass percentage in the NR matrix due to increasing the amount of the agglomeration. In that case, the viscosity of the NR matrix raises.

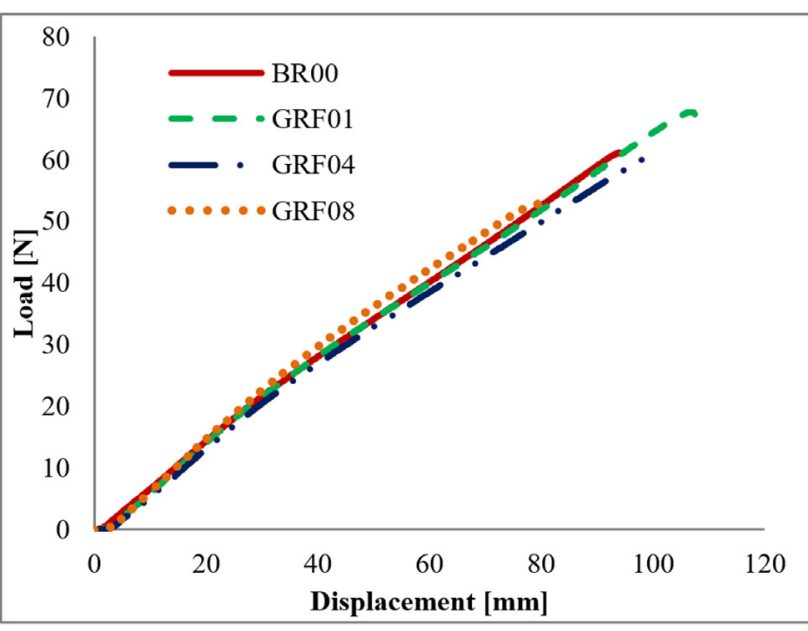

Fig. 11 Tearing test results.

Table 3 Cure characteristics of the NR compounds $\left(* \mathrm{M}_{\mathrm{H}}=\right.$ maximum torque, $\mathrm{M}_{\mathrm{L}}=$ minimum torque, $\mathrm{t}_{\mathrm{s} 2}=$ scorch time, $\mathrm{t}_{90}=$ optimum vulcanization time)

\begin{tabular}{lcccccc}
\hline Compounds & $\begin{array}{c}\text { FEF } \\
\text { N.550 } \\
(\mathrm{phr})\end{array}$ & $\begin{array}{c}\mathrm{NGP} \\
(\mathrm{phr})\end{array}$ & $\begin{array}{c}\mathrm{M}_{\mathrm{L}} \\
(\mathrm{dNm})\end{array}$ & $\begin{array}{c}\mathrm{M}_{\mathrm{H}} \\
(\mathrm{dNm})\end{array}$ & $\begin{array}{c}\mathrm{t}_{\mathrm{s} 2} \\
(\mathrm{~min})\end{array}$ & $\begin{array}{c}\mathrm{t}_{90} \\
(\mathrm{~min})\end{array}$ \\
\hline BR00 & 67.8 & 0 & 1.69 & 13.26 & 2.53 & 5.34 \\
GRF01 & 59.8 & 1 & 1.91 & 12.82 & 2.54 & 5.35 \\
GRF04 & 59.8 & 4 & 2.02 & 13.14 & 2.55 & 5.36 \\
GRF08 & 59.8 & 8 & 2.02 & 12.96 & 2.56 & 5.32 \\
\hline
\end{tabular}

\subsection{Characterization of NR/NGP Nanocomposites}

The morphology of NR/NGP nanocomposites was examined by SEM (Vega3 Tescan Instrument) with an acceleration voltage of $20 \mathrm{kV}$. Before testing, these samples were sputter coated with $\mathrm{Au}$.

Fig. 13 shows the SEM images of the tensile fractured surfaces of the unfilled NR and the NR/NGP nanocomposite with 4 phr of NGP. It can be seen that the section surface of the vulcanized unfilled NR is flat and smooth (Fig. 13a). However, the surface of the NR/NGP nanocomposite with 4 phr of NGP (Fig. 13b) is very rough compared with unfilled NR. Flakes of the NGPs can be seen being well distributed in the NR matrix and protruding from the surfaces.

The morphology of the CB is, however, slightly different consisting of agglomerates of nano-sized particles of the order of 40-55 nm in diameter, near to the resolution limit of the scanning electron microscope.

SEM micrographs of the cross-section of NR/NGP Nanocomposites and cord fiber are presented in Fig. 14. As seen from the cross-section morphology, the NGP was uniformly oriented concerning the around of cord fiber strand. However, NR matrix material cannot infuse all single fibers surfaces, and all spaces between single fibers 

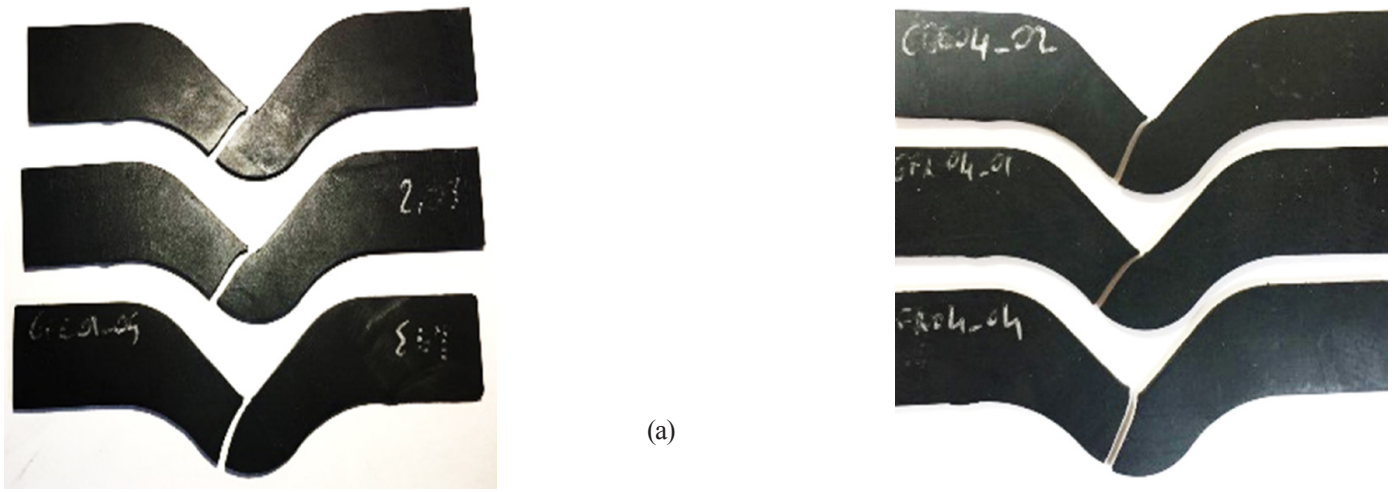

(b)
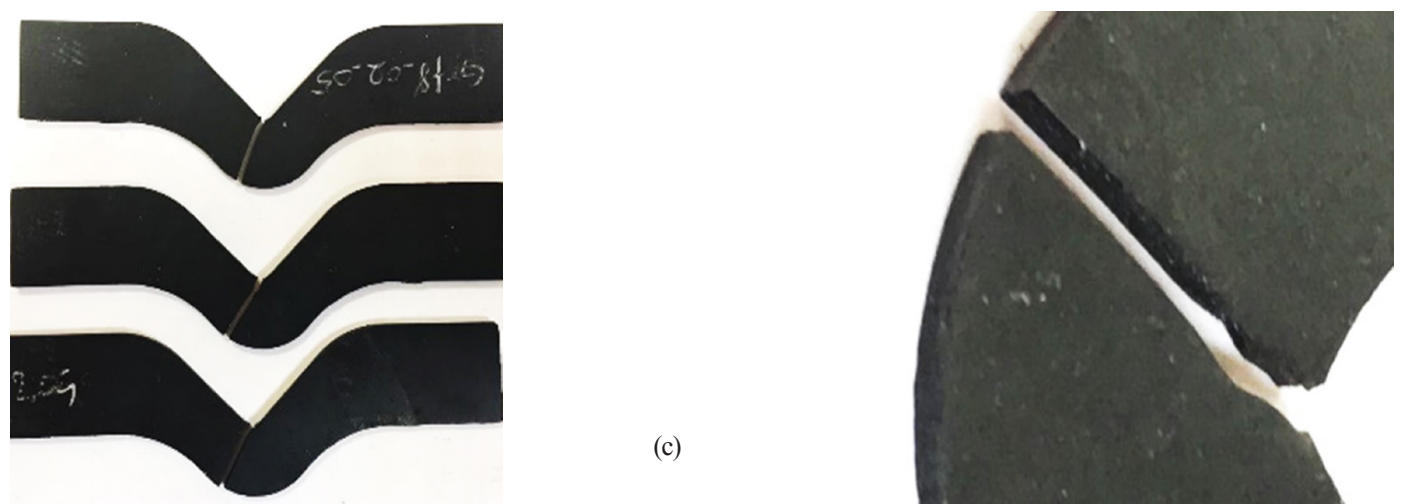

(d)

Fig. 12 The failure of tear specimens a) GRF01 b) GRF04 c) GRF08 d) Detail of typical crack initiation and propagation path of the specimens.
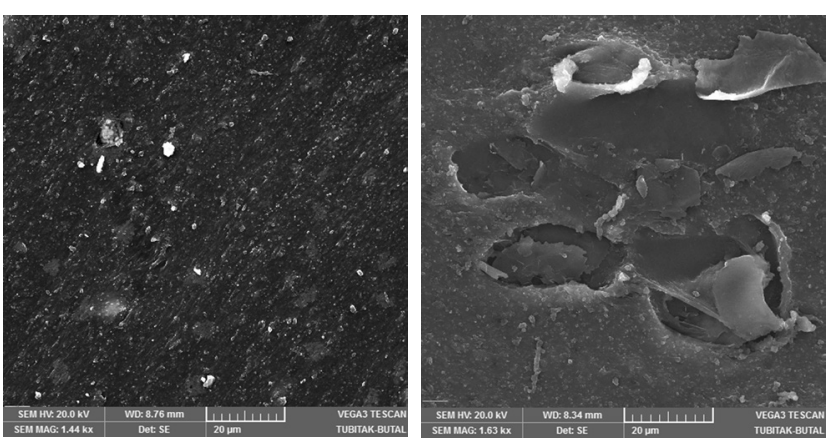

(a)

(b)

Fig. 13 SEM micrographs of NR/NGP nanocomposites tensile fractured surfaces a) Vulcanized unfilled NR b) NR/NGP nanocomposite for $4 \mathrm{phr}$ NGP reinforcement.

in the cord fiber strand, for that reason, the cross-section shows that a porous structure.

\subsection{Electrical Characterizations}

Two different type specimens such as NR/NGP nanocomposites and NR/NGP nanocomposites layered with cord fabrics. Fig. 15 shows an example of the measurement setup. Dumbbell type specimens were used in all electrical properties test. The four-point probe method was implemented to measure the change in electrical resistance of the specimen.
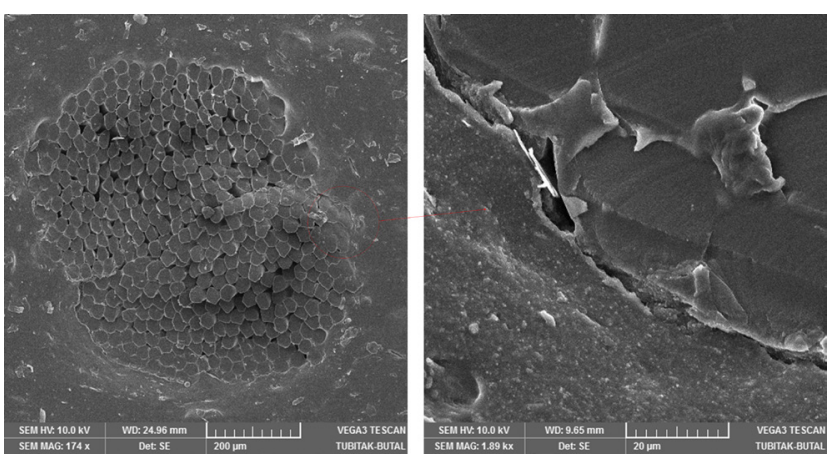

Fig. 14 SEM micrographs of NR/NGP nanocomposites/Cord Fabric laminates.

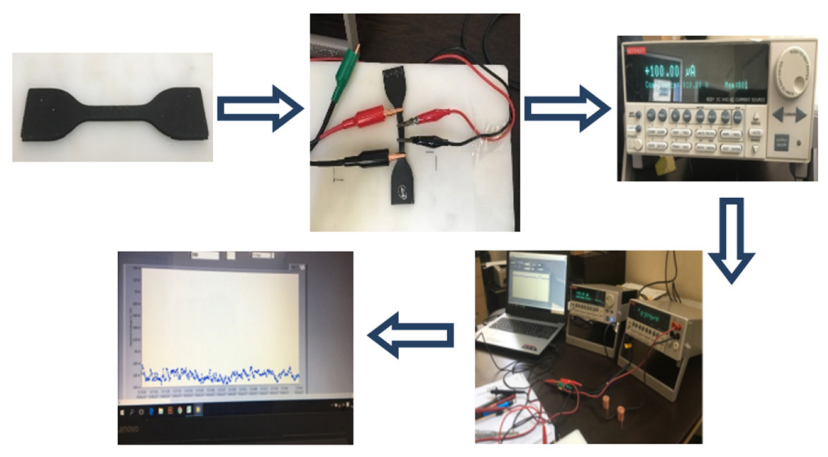

Fig. 15 Electrical properties measurement for free Specimen. 
This method eliminates measurement errors due to the probe resistance, the spreading resistance under each probe, and the contact resistance between each metal probe and the NR/NGP nanocomposite material. The probe array is usually placed in the center of the material, as shown in Fig. 6.

A constant DC was supplied through the outer probes of the specimen using a constant current source (Keithley Instruments Model 6221). Electrometers (Keithley Instruments Model 6514) measure the voltage at each of the inner probes independently, where the difference between the readings is the voltage drop across the zone of interest. The voltage drop was recorded through a digital multimeter (Keithley Instruments Model 2000) and transferred to a data file via a LabVIEW data acquisition software program. Resistance $\mathrm{R}$ is calculated through Ohm's Law using the constant supplied current I and measured voltage V.

Two different samples were used for each test. Each test time for static measurement was $10 \mathrm{~min}$. Experiments were performed at $10 \mathrm{~mA}$ constant current and $10 \mathrm{~V}$ constant voltage.

Fig. 16 and Fig. 17, show electrical resistivity change according to NGP ratio (phr). These figures show as for the electrical conductivity improvement can be obtained in all NGP percentage. These figures show electrical resistivity change according to NGP filler ratio (phr). The conductivity of the NR/NGP composites were improved depending on NGP percentage in both type of materials.

It is exciting that, by incorporation of the only $8 \mathrm{phr}$ NGP into the NR matrix, the electrical resistivity of the NR material was reduced almost $50 \%$ in NR/NGP nanocomposite sheets and more than $60 \%$ reduction in cord fabric reinforced NR/NGP nanocomposites.

\subsection{Electrical properties under Cycling Loading Experiments}

NR/NGP nanocomposite and NR/NGP nanocomposite / cord fabric reinforced composites were subjected to cyclic tensile loading experiments. Each experiment duration for cycling measurement was 10 minutes. Experiments were performed at $10 \mathrm{~mA}$ constant current and $10 \mathrm{~V}$ constant voltage. In Fig. 6 shows cyclic loading experimental setup and electrical connections on the specimen.

The distance between the grips was $80 \mathrm{~mm}$. During dynamic loading the specimen compressed to $20 \mathrm{~mm}$ distance and then waited for a while then returned to the original free conditions.

The fluctuation on the signal during waiting period was minimal comparing with characteristic picks. From

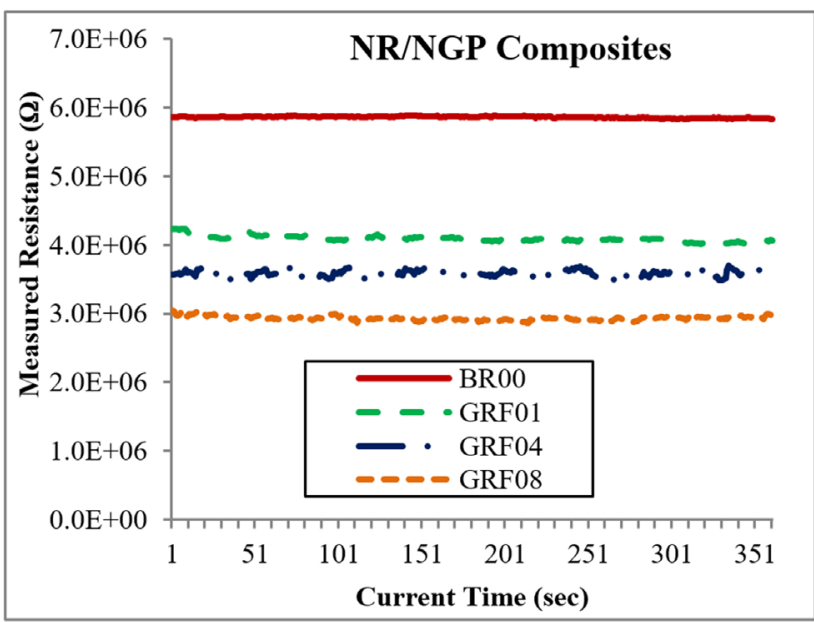

Fig. 16 Comparison of measured electrical resistance concerning NGP ratio.

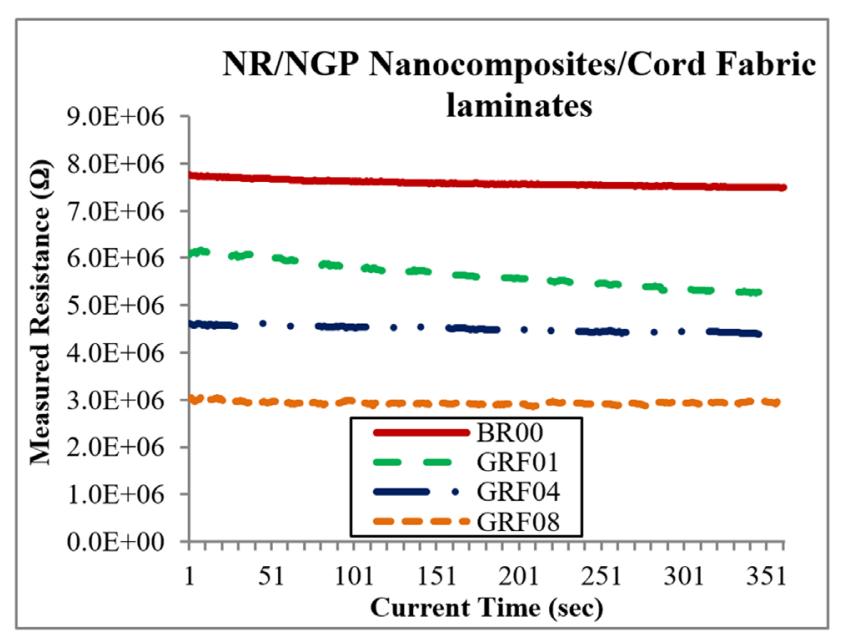

Fig. 17 Comparison of measured electrical resistance concerning NGP ratio, NR-NGP nanocomposites.

Fig. 18 to 21, a lower signal for NGP/NR nanocomposites and higher signals for NGP/NR layered with PA6.6 cord fabrics. This show that, the cord fabric reinforcement regulated the resistance variation by loading change in the NGP/NR nanocomposites. These signals were more precise and more useful for cyclic loading sensing.

\section{Conclusion}

In this study electrical conductive rubber based nanocomposites with and without a cord fabric reinforcement were developed. The mechanical and physical properties of the both composite plates were carried out. Electrical characterizations were obtained under free and cyclic loading conditions. The achieved conclusions were given as below:

- Amount of the absorbed energies were affected by the addition of the Nano Graphene Platelets in different characters. In the 1 phr Nano Graphene Platelets 


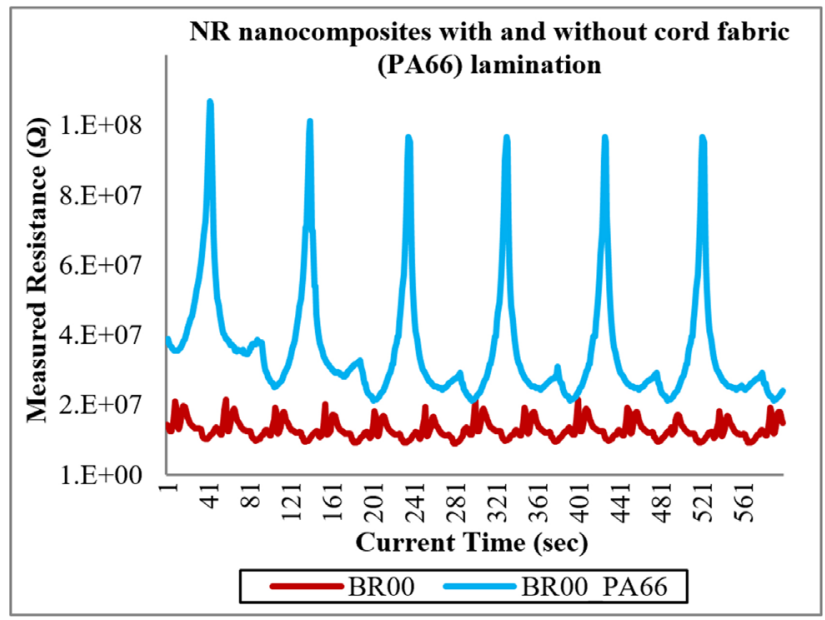

Fig. 18 Cyclic loading electrical resistivity measurement during $10 \mathrm{~min}$ for NR/NGT nanocomposites with and without cord fabric reinforcement (BR00)

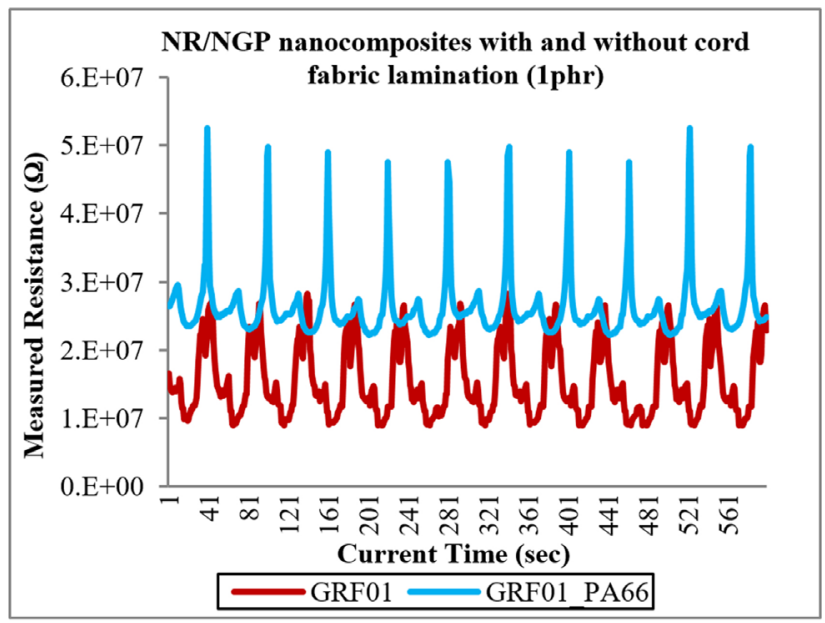

Fig. 19 Cyclic loading electrical resistivity measurement during $10 \mathrm{~min}$ for NR/NGT nanocomposites with and without cord fabric reinforcement (1 phr NGP).

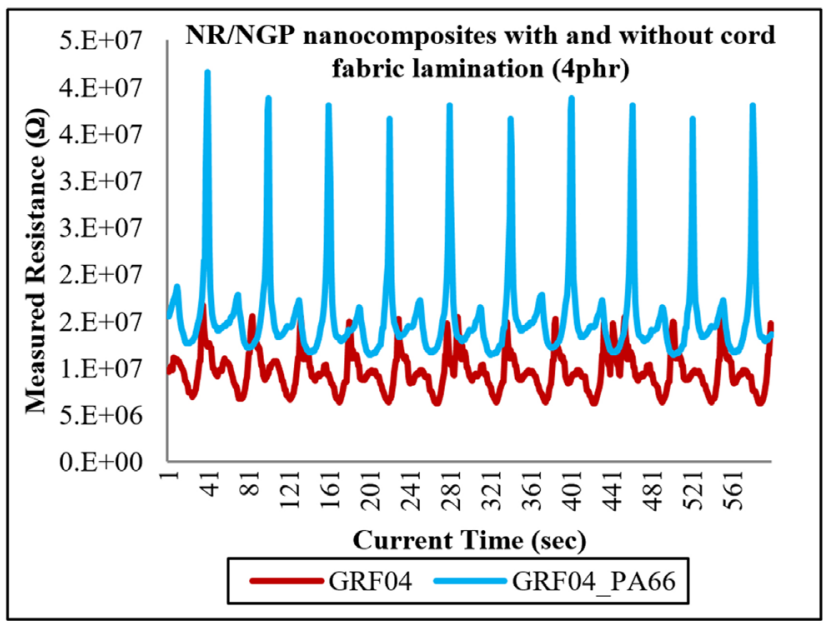

Fig. 20 Cyclic loading electrical resistivity measurement during $10 \mathrm{~min}$ for NR/NGT nanocomposites with and without cord fabric reinforcement (4 phr NGP)

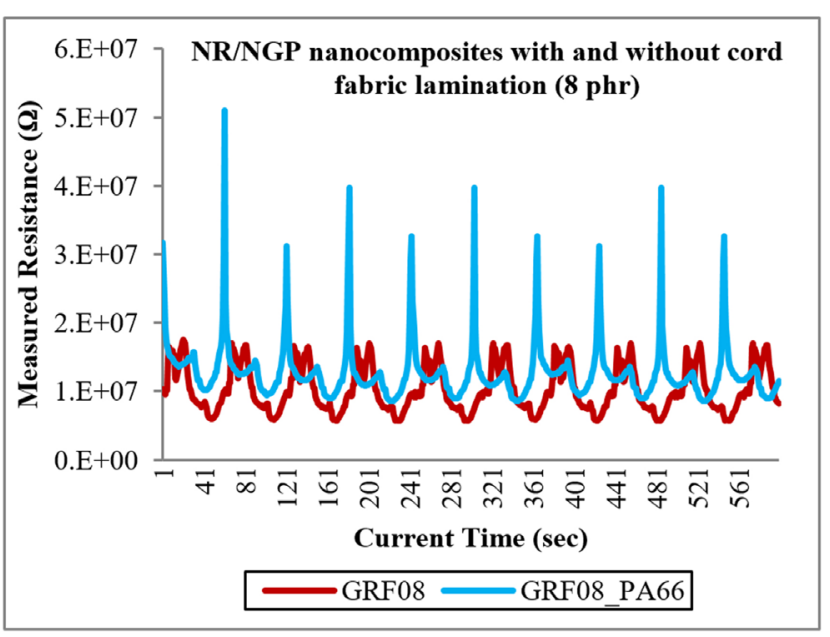

Fig. 21 Cyclic loading electrical resistivity measurement during $10 \mathrm{~min}$ for NR/NGT nanocomposites with and without cord fabric reinforcement ( $8 \mathrm{phr}$ NGP).

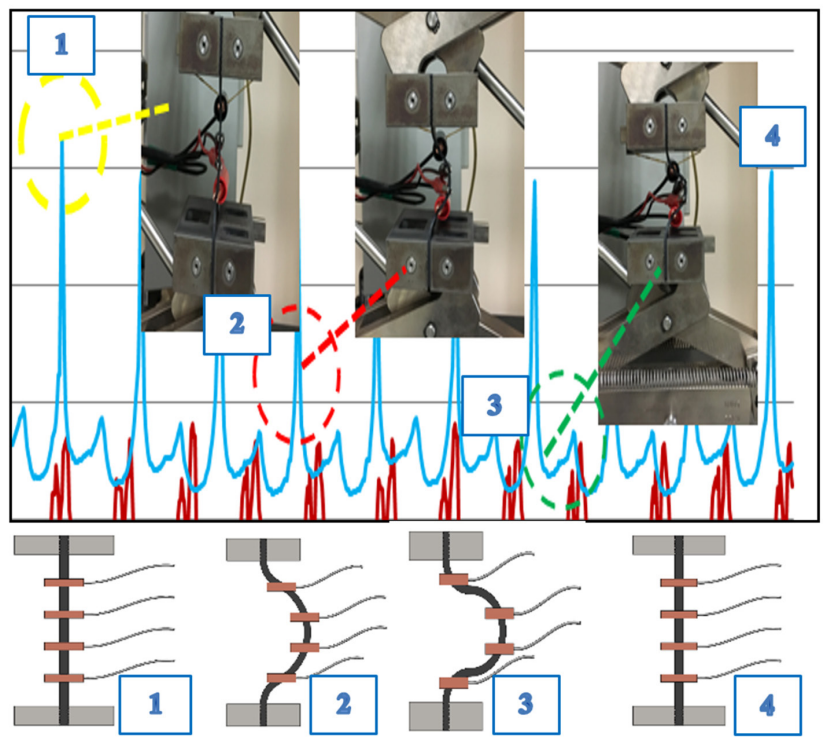

Fig. 22 Cyclic loading experiment conditions during electrical resistivity measurement.

filling, the energy absorption is lower than the base rubber. However, 4 and 8 phr Nano Graphene Platelets addition were improved the amount of the energy absorption of the Natural Rubber.

- Nano Graphene Platelets addition was reduced the tensile strength and maximum strain of the Natural Rubber matrix.

- Tensile strength and strain were not changed by Nano Graphene Platelets addition around used content ratios.

- The electrical conductivity of the Natural Rubber can be improved in all used material configurations.

- Tear strength of the Nano Graphene Platelets / Natural Rubber nanocomposites does not vary due 
to Nano Graphene percentage by a considerable amount. The Graphene or carbon blacks nanoparticles produce secondary cracks and tear crack propagation shows to crack coupling.

- Electrical performance of the all developed nanocomposites shows sensitivity during cycling loading in the

\section{References}

[1] Lee, J.-Y., Kumar, V., Tang, X.-W., Lee, D.-J. "Mechanical and electrical behavior of rubber nanocomposites under static and cyclic strain", Composites Science and Technology, 142, pp. 1-9, 2017. https://doi.org/10.1016/j.compscitech.2017.01.023

[2] Al-Akhras, M.-A., Saq'an, S., Ghadieh, Z. "Ac Electrical Properties of Polystyrene / Ferroelectric Barium Stannate Titanate $\mathrm{Ba}\left(\mathrm{Ti}_{0.9}\right.$ $\left.\mathrm{Sn}_{0.1}\right) \mathrm{O}_{3}$ Ceramic Composite", Acta Physica Polonica A, 130(1), pp. 447-449, 2016.

https://doi.org/10.12693/APhysPolA.130.447

[3] Mansoor, M., Shahid, M. "Fractographic Evaluation of Crack Initiation and Growth in Al-CNTs Nanocomposite Fabricated by Induction Melting", Acta Physica Polonica A, 128(2-B), pp. B-276-B-278, 2015.

https://doi.org/10.12693/APhysPolA.128.B-276

[4] Lin, Y., Dong, X., Liu, S., Chen, S., Wei, Y., Liu, L. "GrapheneElastomer Composites with Segregated Nanostructured Network for Liquid and Strain Sensing Application", ACS Applied Materials \& Interfaces, 8(36), pp. 24143-24151, 2016. https://doi.org/10.1021/acsami.6b08587

[5] Evcin, A., Bezir, N. Ç., Kayalı, R., Kaşıkçı, M., Oktay, A. "Characteristic Properties of Dy-Eu-Ag co-Doped $\mathrm{TiO}_{2}$ Nanoparticles Prepared by Electrospinning Processes", Acta Physica Polonica A, 128(2-B), pp. B-303-B-306, 2015. https://doi.org/10.12693/APhysPolA.128.B-303

[6] Dong, B., Wu, S., Zhang, L., Wu, Y. "High-Performance Natural Rubber Composites with Well-Organized Interconnected Graphene Networks for Strain-Sensing Application", Industrial \& Engineering Chemistry Research, 55(17), pp. 4919-4929, 2016. https://doi.org/10.1021/acs.iecr.6b00214

[7] Novoselov, K. S., Fal'ko, V. I., Colombo, L., Gellert, P. R., Schwab, M. G., Kim, K. "A roadmap for graphene", Nature, 490(7419), pp. 192-200, 2012.

https://doi.org/10.1038/nature11458 same amplitude and periodical character. That means this kind of materials can be used as fatigue sensors.

- Cord fabric reinforcement of NGP/NR regulated the acquired electrical signals, and the signals were obtained more clear and regular than the NGP/NR nanocomposite sheets.

[8] Klüppel, M., Möwes, M. M., Lang, A., Plagge, J., Wunde, M., Fleck, F., Karl, C. W. "Characterization and Application of Graphene Nanoplatelets in Elastomers", In: Stöckelhuber, K. W., Das, A., Klüppel, M. (eds.) Designing of Elastomer Nanocomposites: From Theory to Applications, Advances in Polymer Science, 1st ed., Springer International Publishing, Cham, Germany, 2016, pp. 319-360.

https://doi.org/10.1007/12_2016_1

[9] Zhou, Y., Ge, L., Fan, N., Dai, L., Xia, M. "Cure characteristics, mechanical, thermal, and coloring properties of natural rubber / dye-loaded shell powder composites", Journal of Applied Polymer Science, 135(4), pp. 45750, 2018.

https://doi.org/10.1002/App.45750

[10] Shi, X., Lian, C., Shang, Y., Zhang, H. "Evolution of the dynamic fatigue failure of the adhesion between rubber and polymer cords", Polymer Testing, 48, pp. 175-182, 2015.

https://doi.org/10.1016/j.polymertesting.2015.10.014

[11] The standard rubber "thestandardrubber.com", [online]. Available at: http://www.thestandardrubber.com/SVR10_specifications.shtml [Accessed: 11 January 2018]

[12] Reflex Elastomers "Styrene Butadiene Rubber", [online]. Available at: http://www.relflex.in/styrenebutadienerubber.html [Accessed: 11 January 2018]

[13] Elkim Rubber and Chemical Industry Company "CBR-1203", [online]. Available at: http://www.elkimkaucuk.com.tr/EN/urun. asp?anacat $I D=4 \&$ cat ID $=12 \& u I D=71 \& u r u n=$ cbr-1203 [Accessed: 11 January 2018]

[14] Nanografi "Graphene Nanoplatelet, $99.9+\%, 5$ nm, S. A: 170 m2/g Dia: $18 \mu \mathrm{m}$ ", [online]. Available at: https://nanografi.com/ graphene/graphene-nanoplatelet-99-5-6-nm-s-a-150-m2-g-dia16-m/ [Accessed: 11 January 2018] 